\title{
Autosomal recessive spondylometaphyseal dysplasia, Mégarbané type
}

INSERM

\section{Source}

INSERM. (1999). Orphanet: an online rare disease and orphan drug data base. Autosomal recessive spondylometaphyseal dysplasia, Mégarbané type. ORPHA:401979

Autosomal recessive spondylometaphyseal dysplasia, Mégarbané type is a rare, primary bone dysplasia characterized by intrauterine growth retardation, pre- and postnatal disproportionate short stature with short, rhizomelic limbs, facial dysmorphism, a short neck and small thorax. Hypotonia, cardiomeg aly and global developmetal delay have also been associated. Several radiog raphic findings have been reported, including ribs with cupped ends, platyspondyly, square iliac bones, horizontal and trident acetabula, hypoplastic ischia, and delayed epiphyseal ossification. 